\title{
EXPANSÃO DA EDUCAÇÃO, INTENSIFICAÇÃO E PROLETARIZAÇÃO DO TRABALHO DOCENTE EM PORTUGAL NO SÉCULO XXI
}

\section{Belmiro Gil Cabrito ${ }^{1}$}

\begin{abstract}
RESUMO: A procura de educação cresceu significativamente em Portugal desde a Revolução Democrática de 1974. Essa procura tem vindo a diminuir desde o início do séc. XXI em consequência da diminuição da taxa de natalidade e particularmente no ensino superior, da profunda crise económica que o país vive desde 2008, que lançou milhares de famílias no desemprego e de empresas na falência, dificultando o acesso e a frequência dos jovens dos estratos sociais mais desfavorecidos. No que respeita aos docentes, inicialmente o seu número aumentou respondendo à procura de educação; num segundo momento, na sequência de medidas de austeridade tomadas pelo governo para resolver a crise económica do país, ocorreu a diminuição do seu número ao mesmo tempo que o governo congelou os salários. Neste artigo analisa-se alguns indicadores macroeconómicos e educativos partindo das estatísticas oficiais e conclui-se que as medidas tomadas pelo governo se saldaram na intensificação e proletarização do trabalho docente.
\end{abstract}

Palavras-chave: Educação - Demanda Educacional - Intensificação do Trabalho Proletarização - Trabalho Docente.

\footnotetext{
${ }^{1}$ Licenciado em Economia (1972) e em Ciências Sociais e Políticas (1978) pela Universidade Técnica de Lisboa. Mestre (1994) e Doutor (2000) em Ciências da Educação pela Universidade de Lisboa. Professor Associado aposentado do Instituto de Educação da Universidade de Lisboa (IEUL). Ex-coordenador dos programas de Mestrado e de Doutoramento em Ciências da Educação, área de especialização "Educação de Adultos" do IEUL. Coordenador do grupo de investigação em Educação de Adultos da UIEDEF do IEUL. Presidente da Direcção da Associação de Estudos e Publicações em Educação (EDUCA) da Faculdade de Psicologia e de Ciências da Educação da Universidade de Lisboa. Presidente do Conselho Fiscal da AFIRSE Portugal. Investigador Principal/Investigador em projectos de investigação nas áreas da educação de adultos, formação profissional, gestão e financiamento da educação e da formação, e economia da educação. E-mail: b.cabrito@ie.ulisboa.pt
} 


\title{
EXPANSION OF EDUCATION AND INTENSIFICATION AND PROLETARIANIZATION OF TEACHING WORK IN PORTUGAL IN THE $21^{\text {ST }}$ CENTURY
}

\begin{abstract}
The demand for education has grown significantly in Portugal since the 1974 Democratic Revolution. This demand declined since the beginning of the $21^{\text {st }}$ century because of the decrease in the birth rate and, particularly in higher education as a result of the deep economic crisis that the country has been experiencing since 2008, which launched thousands of families in unemployment and companies in bankruptcy, making access and attendance difficult for young people from most disadvantaged social strata. Concerning teachers their numbers increased at first, responding to the demand for education; In a second moment, following austerity measures taken by the government to solve the economic crisis of the country, their number declined while government imposed a freeze on wages. In the article, we analyze those situations based on the official data and it is concluded that the governmental measures have resulted in the intensification and proletarianization of the teaching work.
\end{abstract}

Key-words: Education - Educational Demand - Intensification of Work Proletarianization - Teaching Work.

\section{Introdução}

Os caminhos sociopolíticos do Portugal contemporâneo podem caraterizar-se sumariamente com duas palavras: elitismo e democratização.

Ao longo de cinco décadas, entre 1926 e 1974, Portugal viveu um regime de ditadura onde predominava o obscurantismo e a ignorância. A inexistência de escolaridade obrigatória e as dificuldades por que passavam a maior parte das famílias, afastavam da escola uma boa parte das crianças em idade escolar. E se, gradualmente, os filhos das famílias oriundas dos estratos mais desfavorecidos foram encontrando essa "escola", tal não acontecia com os outros, os filhos dos estratos que serviam o poder, para os quais, na prática, a escola era destinada. Os herdeiros do regime, aqueles que deveriam ser os novos gestores e mandantes da nova ordem estabelecida. De facto, finda a instrução primária (4 anos), estes jovens podiam usufruir do ensino liceal (5 anos) a que se seguia a universidade e se é verdade que todas as crianças eram livres de fazer a instrução primária e continuar estudos, também é verdade que os custos associados à frequência da escola impediam muitas crianças de usufruir dela num verdadeiro processo de decisão condicionado pela herança cultural (Boudon, 1973). Neste longo período de ignorância e de privação dos mais elementares direitos dos cidadãos, a escola era altamente elitista (Mónica, 1978) e a universidade era frequentada, em mais de $90 \%$, pelos filhos dos indivíduos ligados ao poder (Cabrito, 2002). 
Em 1974, a 25 de Abril, aconteceu a Revolução dos "Cravos", a Revolução Democrática, cujo lema era: Democratização, Desenvolvimento e Descolonização. Com a Revolução, a guerra colonial que Portugal sustentava há 13 anos com as suas colónias (à data, Guiné Bissau, Cabo Verde, Angola, São Tomé e Príncipe, Moçambique e Timor, que se tornaram independentes; Goa, Damão e Dio, territórios que foram integrados na União Indiana; e, Macau, que foi integrado na República Popular da China), chegou ao fim com a independência daqueles territórios, novos países de Língua Oficial Portuguesa que hoje formam, com o Brasil e Portugal, a Comunidade dos Países de Língua Oficial Portuguesa - CPLP.

A partir de 1974, em Portugal a palavra "democratização" tomou corpo numa pluralidade de dimensões e concretizou-se num inúmero conjunto de Direitos, Liberdades e Garantias assentes na Declaração Universal dos Direitos do Homem e vertidos na Constituição da República Portuguesa, em 1976.

Um dos direitos tornados fundamentais dos portugueses foi, exactamente, $o$ da educação. 0 sistema educativo expandiu-se e reformulou-se. Foi estabelecida a escolaridade obrigatória (inicialmente de 6 anos; de 9 anos, a partir de 1986 com a publicação da Lei de Bases do Sistema Educativo; de 12 anos, a partir de 2008 sendo gratuita a frequência de todos os níveis de ensino, nas escolas públicas); diversificou-se a oferta de educação superior, com o estabelecimento do ensino superior politécnico; aumentou a oferta deste nível de ensino e, como resposta, os portugueses procuraram de forma explosiva, por educação.

0 ensino básico e secundário (respetivamente, o ensino fundamental e o ensino médio, no Brasil) cresceram a um ritmo alucinante. 0 ensino superior acompanhou essa procura. Na verdade, assiste-se a um processo de procura de educação bem ajustado às mais-valias que a educação parece atribuir, seja em termos de equidade e de combate às desigualdades sociais (Bourdieu e Passeron, 1964), seja na produtividade e no aumento salarial dos trabalhadores (Becker, 1964; Schultz, 1961).

Neste artigo, dá-se conta deste processo de evolutivo da procura social de educação desde 1974, seu crescimento nas primeiras décadas do novo regime e estagnação/decréscimo na última década e analisa-se, também, a evolução do número de docentes que acompanhou todo o processo, no sentido de perceber se a classe docente tem vindo a conhecer a dignificação do seu trabalho medido, basicamente, pela evolução salarial e intensificação do trabalho. 


\section{A educação em Portugal desde finais do séc. XX: explosão e contração}

\subsection{Evolução do nível de qualificação académica da população portuguesa}

Portugal sofreu um atraso histórico secular em relação à educação e, em particular, ao ensino superior apresentando nos anos da década de 1970 um atraso significativo em comparação com a maioria dos países europeus. Após a mudança de regime decorrente da Revolução dos "Cravos" a 25 de abril de 1974 inicia-se um período de mudança acelerada em todos os sectores e domínios no país, nomeadamente no educativo.

No ensino básico e secundário, assiste-se ao estabelecimento e alargamento da escolaridade obrigatória. No ensino superior se procura recuperar os efeitos de muitas décadas de abandono e de desinvestimento, assistindo-se logo na década de 1970, à criação do Ensino Superior Politécnico, sistema de ensino superior não universitário, tendo-se assistido também, ainda nesta década e na seguinte à criação de novos estabelecimentos de ensino superior público (7 universidades, a acrescer às 4 universidades já existentes; 15 institutos superiores politécnicos; e, um instituto universitário).

Em 1986, face à incapacidade (ou decisão camuflada dos centros de poder) de o ensino superior público não satisfazer a procura de ensino superior, este nível de ensino foi aberto à iniciativa privada, tendo-se assistido à criação de dezenas de novas universidades e de institutos superiores.

Toda esta procura de educação se repercutiu, naturalmente, no nível de qualificação académica dos Portugueses. Dê-se atenção aos quadros que seguem. 
Tabela 01 - Taxa bruta de escolarização, por nível de ensino, em \% (*)

\begin{tabular}{|c|c|c|c|c|c|c|}
\hline \multirow[t]{3}{*}{ Anos } & \multicolumn{6}{|c|}{ Nível de ensino } \\
\hline & \multirow{2}{*}{$\begin{array}{l}\text { Educação } \\
\text { Pré-Escolar }\end{array}$} & \multicolumn{4}{|c|}{ Ensino Básico } & \multirow{2}{*}{$\begin{array}{c}\text { Ensino } \\
\text { Secundário }\end{array}$} \\
\hline & & Total & 10 ciclo & 20 ciclo & 3ㅇc ciclo & \\
\hline 1961 & 1,2 & 70,2 & 130,7 & 23,1 & 20,2 & 2,8 \\
\hline 1971 & 2,9 & 88,1 & 135,3 & 58,8 & 39,5 & 5,9 \\
\hline 1981 & 15,4 & 100,4 & 136,2 & 90,8 & 59,2 & 32,8 \\
\hline 1990 & 44,6 & 112,0 & 128,9 & 122,0 & 87,5 & 60,9 \\
\hline 2000 & 73,3 & 122,1 & 123,6 & 123,2 & 119,6 & 102,1 \\
\hline 2005 & 78,3 & 117,4 & 118,6 & 124,7 & 111,5 & 107,6 \\
\hline 2008 & 79,8 & 121,3 & 113,3 & 123,2 & 130,8 & 101,0 \\
\hline 2010 & 85,0 & 127,1 & 107,5 & 124,5 & 156,1 & 146,2 \\
\hline 2015 & 90,9 & 110,3 & 103,5 & 113,7 & 116,4 & 117,4 \\
\hline
\end{tabular}

Os números do Tabela 01 são elucidativos do crescimento da população escolar após a Revolução Democrática de 1974. Neste quadro é apresentada a Taxa bruta de escolarização, sendo que essa taxa representa a relação percentual entre o número total de alunos matriculados num determinado ciclo de estudos (independentemente da idade) e a população residente em idade normal de frequência desse ciclo de estudo, facto que explica taxas de valor superior a $100 \%$ e que evidencia a procura de educação por parte de indivíduos que não puderam estudar aquando da idade normal.

Os dados mostram um crescimento vertiginoso da frequência de todos os níveis de ensino. Se, em 1961, a taxa bruta de escolarização no ensino secundário era, apenas, de 2,8\%, esse valor fixa-se, em 2015, nos 117,4\%. Este crescimento é visível em todos os graus de ensino demonstrando uma população sedenta por educação a que não será estranho, como nos ensina Bourdieu e Passeron (1964) 
ou Baudelot e Estabelet (1971), a ligação existente entre educação, trabalho e estatuto social ou, na senda de Becker (1964) e Schultz (1961) com a teoria de capital humano, a relação entre educação, produtividade e salários.

De registar, todavia, a evolução negativa dos valores desta taxa em todos os níveis de ensino, à excepção da educação pré-escolar, nos últimos anos e que se explica, basicamente, pela crise económica que o país tem vindo a sentir desde 2008 e que levou muitos portugueses adultos a abandonar estudos em virtude de entrarem numa situação de desemprego ao mesmo tempo que o governo do país no período mais difícil da crise (2011-2105), um governo de centro-direita apostado em diminuir as despesas públicas, tomou medidas altamente perniciosas para o país em geral nomeadamente para a educação, ao abandonar as formas então existentes de educação de jovens fracamente escolarizados e de adultos (ofertas educativas assentes, basicamente, nos princípios de aprendizagem experiencial, concretizadas no reconhecimento, validação e certificação de competências) sem que tivesse apresentado qualquer alternativa deixando muitos milhares de portugueses sem qualquer alternativa educativa.

\section{Tabela 02 - Taxa real de escolarização, por nível de ensino (\%) (*)}

\begin{tabular}{|c|c|c|c|c|c|}
\hline \multirow[t]{3}{*}{ Anos } & \multicolumn{5}{|c|}{ Nível de ensino } \\
\hline & \multirow{2}{*}{$\begin{array}{c}\text { Educação Pré- } \\
\text { Escolar }\end{array}$} & \multicolumn{3}{|c|}{ Ensino Básico } & \multirow{2}{*}{$\begin{array}{c}\text { Ensino } \\
\text { Secundário }\end{array}$} \\
\hline & & 10 ciclo & 20 ciclo & 3o ciclo & \\
\hline 1961 & 0,9 & 80,4 & 7,5 & 6,1 & 1,3 \\
\hline 1971 & 2,8 & 83,7 & 22 & 14,7 & 4,3 \\
\hline 1981 & 17,8 & 100,0 & 41,1 & 26,2 & 12,4 \\
\hline 1990 & 41,7 & 100,0 & 69,2 & 54,0 & 28,2 \\
\hline 2000 & 71,6 & 100,0 & 87,4 & 83,9 & 58,8 \\
\hline 2005 & 77,4 & 100,0 & 86,4 & 82,5 & 59,8 \\
\hline 2008 & 79,0 & 100,0 & 92,0 & 86,2 & 63,2 \\
\hline 2010 & 83,9 & 100,0 & 93,8 & 89,5 & 71,4 \\
\hline 2015 & 88,5 & 96,6 & 88,5 & 86,5 & 74,6 \\
\hline \multicolumn{6}{|c|}{ Fontes/Entidades: DGEEC/MEd - MCTES | INE, PORDATA } \\
\hline
\end{tabular}


Os valores do Tabela 02, que apresenta a evolução da taxa real de educação, reforçam o movimento intenso de procura social de educação que o país tem vindo a conhecer e o cumprimento, pelo Estado, de uma das suas funções sociais. Observe-se o Tabela 02.

Os valores do quadro mostram que o sistema educativo português, no caso da escolaridade obrigatória, apesar do sucesso e dinamismo que denotam, ainda não está a desempenhar o seu papel na totalidade dado não ter atingido os $100 \%$ dos jovens dos respectivos níveis etários, em todos os ciclos. Este não conseguimento resulta por razões diferentes no que respeita os diversos níveis de ensino. No que respeita à educação pré-escolar, sublinhe-se que este nível de ensino só foi tornado obrigatório, apenas a partir dos 5 anos, em 2015 encontrando-se, pois, ainda em expansão. Já no que respeita o ensino básico, que atingia quase os $100 \%$ dos jovens em idade escolar entre os 6 e os 15 anos, a evolução negativa ocorrida entre 2010 e 2015 é fruto das consequências das políticas de austeridade governamentais; o mesmo se pode dizer acerca da evolução da taxa real do ensino secundário, que conheceu um forte abrandamento no período da crise, por razões similares devendo relembrar-se, todavia, que este nível de ensino se tornou obrigatório apenas a partir de 2008 o que explica, também, os valores ainda baixos que apresentam.

Em termos gerais, a evolução negativa registada entre 2010 e 2015 pelas taxas bruta e real de escolarização resulta das condições de vida que as políticas de austeridade trouxeram aos portugueses determinada por uma diminuição brutal do consumo interno e uma economia altamente deprimida.

\subsection{Evolução da procura social de educação, nas últimas décadas}

Os quadros acima referiam-se à totalidade dos estudantes portugueses, entre os 5 e os 18 anos de idade, isto é, incluíam os jovens matriculados nos estabelecimentos públicos e nos estabelecimentos privados.

Efetivamente, em Portugal existem estabelecimentos públicos e privados de educação pré-escolar e do ensino básico e secundário, sendo que a oferta pública é maioritária e gratuita. Aliás, salvo a educação pré-escolar, a oferta pública atual é suficiente para atender a todas as crianças do ensino obrigatório. Todavia, muitas vezes por razões que se prendem a questões relacionadas com o estatuto social, os encarregados de educação procuram escolas privadas. 
Nos quadros seguintes apresenta-se a evolução do número de matrículas na educação pré-escolar e no ensino básico e secundário, nas últimas décadas, no subsistema de ensino público e no subsistema privado de ensino.

Tabela 03 - Evolução do número de alunos matriculados na educação pré-escolar e no ensino básico e secundário, nas escolas públicas

\begin{tabular}{|c|c|c|c|c|c|c|}
\hline \multirow[t]{3}{*}{ Anos } & \multicolumn{5}{|c|}{ Nível de ensino } & \multirow[t]{3}{*}{ Total } \\
\hline & \multirow{2}{*}{$\begin{array}{l}\text { Educação } \\
\text { Pré-Escolar }\end{array}$} & \multicolumn{3}{|c|}{ Ensino Básico } & \multirow{2}{*}{$\begin{array}{l}\text { Ensino } \\
\text { Secundário }\end{array}$} & \\
\hline & & 1ㅇciclo & 2o ciclo & 3 ciclo & & \\
\hline 1961 & - & 846.024 & 55.952 & 73.748 & 8.360 & 984.084 \\
\hline 1970 & - & 883.681 & 145.925 & 145.702 & 21.220 & 1.196 .528 \\
\hline 1980 & - & 864.517 & 281.660 & 280.834 & 163.829 & 1.590 .840 \\
\hline 1990 & 70.730 & 670.441 & 343.192 & 406.892 & 285.613 & 1.776 .868 \\
\hline 2000 & 113.644 & 489.049 & 248.364 & 382.288 & 354.832 & 1.588 .177 \\
\hline 2005 & 137.307 & 454.458 & 238.122 & 336.593 & 310.762 & 1.477 .242 \\
\hline 2008 & 141.854 & 445.768 & 233.272 & 372.344 & 280.286 & 1.473 .524 \\
\hline 2010 & 141.044 & 424.587 & 236.023 & 409.416 & 369.979 & 1.581 .049 \\
\hline 2015 & 141.571 & 367.667 & 207.369 & 341.527 & 312.497 & 1.370 .631 \\
\hline
\end{tabular}

Fontes/Entidades: DGEEC/MEd - MCTES | INE, PORDATA

Última actualização: 30/11/2016

Os valores do quadro testemunham bem o que se tem vindo a referir acerca da procura de educação. 0 número de estudantes da educação pré-escolar e do ensino básico e secundário cresceu se forma explosiva nas últimas décadas verificando-se, todavia, uma quebra nesse número na última década resultante, particularmente, de duas ordens de razões: a diminuição das taxas de natalidade e as políticas de austeridade conduzidas pelo governo no período 2011-2105. De salientar, todavia, que a quebra demográfica ainda não teve efeitos significativos no que respeita ao ensino secundário pelo que a quebra registada na procura deste nível educativo resultou, basicamente, da crise económica do país e das políticas de austeridade impostas pelo governo. De registar, todavia, que nos últimos anos se observa uma inversão da tendência. 
Veja-se, de seguida, a evolução do número de jovens matriculados em estabelecimentos de ensino privado.

Tabela 04 - Evolução do número de alunos matriculados na educação préescolar e no ensino básico e secundário, nas escolas privadas

\begin{tabular}{|c|c|c|c|c|c|c|}
\hline \multirow[t]{3}{*}{ Anos } & \multicolumn{5}{|c|}{ Nível de ensino } & \multirow[t]{3}{*}{ Total } \\
\hline & \multirow{2}{*}{$\begin{array}{l}\text { Educação } \\
\text { Pré-Escolar }\end{array}$} & \multicolumn{3}{|c|}{ Ensino Básico } & \multirow{2}{*}{$\begin{array}{l}\text { Ensino } \\
\text { Secundário }\end{array}$} & \\
\hline & & 10 ciclo & 2ㅇciclo & 3o ciclo & & \\
\hline 1990 & 90.899 & 45.440 & 27.415 & 37.734 & 23.955 & 225.443 \\
\hline 2000 & 114.815 & 50.894 & 28.165 & 42.076 & 62.873 & 298.823 \\
\hline 2005 & 122.491 & 49.954 & 29.620 & 44.310 & 66.134 & 312.509 \\
\hline 2008 & 124.304 & 52.824 & 30.052 & 52.924 & 69.191 & 329.295 \\
\hline 2010 & 133.343 & 54.932 & 37.225 & 94.279 & 114.003 & 433.782 \\
\hline 2015 & 123.089 & 50.478 & 31.213 & 48.444 & 81.121 & 334.345 \\
\hline
\end{tabular}

Fontes/Entidades: DGEEC/MEd - MCTES | INE, PORDATA

Última actualização: 30/11/2016

À semelhança do que ocorreu no ensino público, também no ensino privado se registou uma evolução crescente desde o século passado sendo que essa tendência se inverteu a partir de 2010, acompanhando a crise por que o país passa. De referir, todavia, que o número de alunos matriculados neste subsistema de ensino sempre foi bastante inferior ao número dos estudantes matriculados no ensino público, com excepção da Educação Pré-Escolar em virtude de neste nível de ensino uma boa parte dos estabelecimentos serem IPSS - Instituições Particulares Sem Fins Lucrativos que são parcialmente financiadas pelo Estado, complementando a oferta pública. Dê-se agora atenção ao que aconteceu com o ensino superior. 


\section{Tabela 05 - Evolução do número de estudantes matriculados no ensino superior, público e privado, em valores absolutos e percentuais}

\begin{tabular}{lrrrrr}
\hline Anos & Total & Ensino Público & & Ensino Privado & \\
\hline 1978 & Número & $\%$ & Número & $\%$ \\
\hline 1980 & 81.152 & 77.501 & 95,5 & 4.081 & 4,5 \\
\hline 1990 & 157.918 & 73.869 & 91,3 & 7.050 & 8,7 \\
\hline 2000 & 373.745 & 255.008 & 68,2 & 118.737 & 31,8 \\
\hline 2005 & 380.937 & 282.273 & 74,1 & 98.664 & 25,9 \\
\hline 2008 & 376.917 & 284.333 & 75,4 & 92.584 & 24,6 \\
\hline 2010 & 383.627 & 293.828 & 76,6 & 89.799 & 23,4 \\
\hline 2011 & 396.268 & 307.978 & 77,7 & 88.290 & 22,3 \\
\hline 2012 & 390.273 & 311.574 & 79,8 & 78.699 & 20,2 \\
\hline 2013 & 371.000 & 303.710 & 81,9 & 67.290 & 18,1 \\
\hline 2014 & 362.200 & 301.654 & 83,3 & 60.546 & 16,7 \\
\hline 2015 & 349.658 & 292.359 & 83,6 & 57.299 & 16,4 \\
\hline 2016 & 356.399 & 297.884 & 83,6 & 58.515 & 16,4 \\
\hline
\end{tabular}

Fontes/Entidades: DGEEC/MEd - MCTES | INE, PORDATA

Última actualização: 22/08/2016

À semelhança do que ocorreu no ensino básico e secundário, também no ensino superior se verificou um crescimento explosivo da procura a que se seguiu, a partir de meados da primeira década do presente século, uma diminuição desse ritmo sendo que a procura diminuiu, mesmo, em valores absolutos nos últimos anos.

Em primeiro lugar, registe-se o crescimento fortíssimo da procura na década de 1980. Por alturas da Revolução de 1974, o número de estudantes do ensino superior rondava os 25.000 (Cabrito, 2002), sendo que apenas uma pequena minoria estudantes frequentava o ensino privado, na única instituição privada de 
ensino superior que existia em Portugal à data: a Universidade Católica Portuguesa que devia a sua existência à Concordata com a Santa Sé.

Até 1986, o ensino superior era maioritariamente público. Em 1986, com a publicação da Lei de Bases do Sistema Educativo, o sistema de ensino superior foi aberto à iniciativa privada que veio absorver os candidatos ao ensino superior que não conseguiam vaga nas universidades e nos institutos superiores politécnicos públicos, em virtude do estabelecimento de um numerus clausus que determinava o número de vagas para cada instituição de ensino e para cada curso, anualmente.

$\mathrm{Na}$ verdade, fruto de um processo de "normalização" da realidade geral e educativa portuguesa, que se concretizou numa viragem política conservadora contra-revolucionária do regime (Barroso, 2002), assistiu-se a diversas medidas de política no âmbito social, nomeadamente no educativo, entre as quais medidas que dificultavam ou impediam a entrada de jovens no ensino superior ao mesmo tempo que se discutia a possível abertura deste nível de ensino à iniciativa privada e alguma forma de privatização do ensino superior público, nomeadamente por influência de organizações internacionais como o Banco Mundial, como veio a acontecer em 1986, com a abertura do sector ao capital privado e em 1992, com o estabelecimento de taxas de frequência actualizadas no ensino superior público (Cabrito, 2016). Deste modo, sucessivos governos prepararam o "nascimento" do ensino superior privado garantindo-lhes um "exército de reserva" de candidatos.

Em consequência, nas décadas seguintes, tendo-se continuado a verificar o ritmo muito rápido da procura de ensino superior, o número de estudantes matriculados nos estabelecimentos privados chegou a ser um terço do total de estudantes deste nível de ensino.

A tendência crescente de procura de ensino superior inverteu-se a partir dos primeiros anos deste século. Indubitavelmente, esta quebra na procura de educação superior deve-se à situação económica do país: face ao aumento do desemprego e às piores condições de vida, muitos jovens não se candidataram ao ensino superior por incapacidade financeira para tal.

De salientar que esta quebra foi mais acentuada no ensino privado o que se explica pela diferença no montante que os estudantes têm de pagar para frequentar o ensino superior público e privado: menos de 1100 euros/ano, nas instituições públicas de ensino superior versus mais de 400 euros/mês nas instituições privadas.

Aliás, a evolução da taxa de desemprego demonstra notoriamente os problemas de emprego que os portugueses sentiram nos "piores" anos da crise 
financeira que afectou toda a população inclusive os indivíduos com qualificação superior.

Tabela 06 - Evolução da taxa de desemprego (\%)

\begin{tabular}{|c|c|c|c|c|c|c|}
\hline \multirow[t]{2}{*}{ Anos } & \multicolumn{3}{|c|}{ Sexo } & \multicolumn{3}{|c|}{ Nível de escolaridade } \\
\hline & Total & Masculino & Feminino & $\begin{array}{l}\text { Ensino } \\
\text { Básico }\end{array}$ & $\begin{array}{c}\text { Ensino } \\
\text { Secundário e } \\
\text { pós secundário }\end{array}$ & $\begin{array}{l}\text { Ensino } \\
\text { Superior }\end{array}$ \\
\hline 1983 & 7,6 & 4,6 & 11,6 & $\operatorname{ad}(*)$ & $\operatorname{ad}(*)$ & $\operatorname{ad}(*)$ \\
\hline 1990 & 4,6 & 3,2 & 6,5 & $\begin{array}{r}5,1 \\
(1998)\end{array}$ & $\begin{array}{r}6,9 \\
(1998)\end{array}$ & $\begin{array}{r}3,4 \\
(1998)\end{array}$ \\
\hline 2000 & 3,9 & 3,1 & 4,9 & 4,2 & 4,6 & 3,1 \\
\hline 2005 & 7,6 & 6,7 & 8,6 & 8,0 & 8,0 & 6,2 \\
\hline 2008 & 7,6 & 6,5 & 8,7 & 7,8 & 7,8 & 6,8 \\
\hline 2010 & 10,8 & 9,8 & 11,9 & 11,7 & 11,4 & 7,0 \\
\hline 2011 & $\perp_{12,7}$ & $\perp_{12,3}$ & $\perp_{13,0}$ & $\perp_{13,7}$ & $\perp_{13,4}$ & $\perp_{9,0}$ \\
\hline 2012 & 15,5 & 15,6 & 15,5 & 16,1 & 17,6 & 11,6 \\
\hline 2013 & 16,2 & 16,0 & 16,4 & 17,0 & 17,4 & 12,6 \\
\hline 2014 & 13,9 & 13,5 & 14,3 & 15,0 & 15,3 & 10,0 \\
\hline 2015 & 12,4 & 12,2 & 12,7 & 13,2 & 13,9 & 9,2 \\
\hline 2016 & 11,1 & 11,0 & 11,2 & 11,8 & 12,2 & 8,4 \\
\hline
\end{tabular}

Fontes/Entidades: INE, PORDATA

Última actualização: 08/02/2017

$(*)$ ad - ausência de dados

$\perp$ - quebra da série

Da análise dos dados do Tabela 06 pode constatar-se, por um lado, o facto de o mercado de trabalho tratar sempre "homens" e "mulheres" de forma desigual, revelando um mercado bastante segmentado (Doeringer e Piore, 1971) com a taxa de desemprego das mulheres a ser superior à dos homens ressalvando-se, todavia, que desde inícios da crise as taxas de desemprego masculino e feminino se tornaram basicamente iguais evidenciando uma situação económica de crise sem precedentes no Portugal democrático. 
Por outro lado, nota-se que a taxa de desemprego foi sempre tanto maior quanto menor o nível de escolaridade dos indivíduos, ainda que o desemprego dos jovens com níveis de educação superior tenha aumentado e registado também níveis nunca vistos desde 1974, situação que explica, aliás, que Portugal seja hoje um exportador de capital humano a custo zero (Cerdeira et al., 2016) para os países desenvolvidos da OCDE, concretizando um verdadeiro processo de fuga de cérebros (Cerdeira et al., 2015; Gomes et al., 2017).

\section{Evolução do número de professores dos ensinos superior e não superior}

Durante alguns anos, a evolução do número de docentes de todos os níveis de ensino evoluiu de forma semelhante à da procura de educação. A partir de $1974 \mathrm{e}$ até meados da década de 1990, o número de professores evoluiu positivamente numa tentativa de responder à procura social de educação. Todavia, nas últimas décadas e, particularmente neste século, o número de docentes tem vindo a diminuir de forma drástica em virtude, por um lado, da diminuição do número de alunos e, por outro e deforma muita vincada, devido à crise financeira que o governo de centro-direita tentou resolver com políticas ultraliberais de austeridade que, no caso dos docentes se materializou em despedimento de milhares de professores e em cortes salariais. Atente-se aos valores do Tabela 07.

\section{Tabela 07 - Número de Docentes do ensino não superior, público e privado}

\begin{tabular}{|c|c|c|c|c|c|c|}
\hline \multirow[t]{3}{*}{ Anos } & \multicolumn{6}{|c|}{ Nível de ensino } \\
\hline & \multirow{2}{*}{ Total } & \multirow{2}{*}{$\begin{array}{l}\text { Educação } \\
\text { Pré-Escolar }\end{array}$} & \multirow{2}{*}{$\begin{array}{l}\text { Ensino } \\
\text { Básico 1o } \\
\text { ciclo }\end{array}$} & \multicolumn{3}{|c|}{ Ensino Básico 2o e 3o ciclos e Secundário } \\
\hline & & & & Total & 2을 Ciclo & $\begin{array}{l}\text { 3o Ciclo e } \\
\text { Secundário }\end{array}$ \\
\hline 1990 & 142.107 & 7.737 & 41.512 & 92.858 & 31.463 & 61.395 \\
\hline 2000 & 175.209 & 15.437 & 39.022 & 120.750 & 35.180 & 85.570 \\
\hline 2005 & 185.157 & 17.797 & 40.619 & 126.741 & 37.164 & 89.577 \\
\hline 2008 & 175.919 & 17.682 & 35.228 & 123.009 & 34.057 & 88.952 \\
\hline 2010 & 179.956 & 18.380 & 34.572 & 127.004 & 35.629 & 91.375 \\
\hline 2015 & 141.274 & 16.079 & 28.095 & 97.100 & 23.747 & 73.353 \\
\hline
\end{tabular}

Fontes/Entidades: DGEEC/MEd - MCTES, PORDATA

Última actualização: 30/06/2016 
Como se pode verificar, o número de docentes do ensino não superior diminuiu de forma muito intensa desde meados da primeira década deste século, particularmente após 2010. Esta diminuição traduziu-se, nomeadamente, no aumento do número médio de alunos por professor, apesar da diminuição registada do número de alunos no sistema. Observe-se o Tabela 08:

\section{Tabela 08 - Evolução do número total de estudantes e de professores do ensino não superior, dos estabelecimentos públicos e privados e rácio no de alunos/professor total e por subsistema de ensino}

\begin{tabular}{|c|c|c|c|c|c|}
\hline Anos & $\begin{array}{c}\text { № total de } \\
\text { alunos }\end{array}$ & $\begin{array}{l}\text { № total de } \\
\text { professores }\end{array}$ & $\begin{array}{c}\text { Rácio no de } \\
\text { alunos/professor } \\
\text { total }\end{array}$ & $\begin{array}{l}\text { Rácio no de } \\
\text { alunos/profess } \\
\text { or, ensino } \\
\text { público }\end{array}$ & $\begin{array}{l}\text { Rácio no de } \\
\text { alunos/profess } \\
\text { or, ensino } \\
\text { privado }\end{array}$ \\
\hline 1990 & 2002311 & 142107 & 14,1 & $14,0(*)$ & $10,8\left(^{*}\right)$ \\
\hline 2000 & 1887000 & 175209 & 10,8 & 10,2 & 15,0 \\
\hline 2005 & 1789751 & 185157 & 9,7 & 9,0 & 14,5 \\
\hline 2008 & 1802819 & 175919 & 10,2 & 9,6 & 15,0 \\
\hline 2010 & 2014831 & 179956 & 11,2 & 10,1 & 18,5 \\
\hline 2015 & 1704976 & 141274 & 12,1 & 11,3 & 16,4 \\
\hline
\end{tabular}

Fontes/Entidades: DGEEC/MEd - MCTES, PORDATA

(*) Não inclui a Educação Pré-Escolar.

Os valores do quadro mostram bem o objectivo dos governos progressistas em assegurar a qualidade do ensino, nomeadamente do ensino público, assistindo-se a uma diminuição significativa do número de alunos por professor, contrariando a evolução posterior a 2005. Assim, em plena crise económica e financeira do país, e apesar da diminuição do número de alunos, sob a égide de governos de centro-direita que desenvolveram políticas ultraliberais de redução da despesa pública, assiste-se nestes últimos anos ao incremento daquele rácio. A evolução deste indicador no ensino privado é semelhante ainda que o número de alunos por professor seja sempre muito superior ao número de alunos por professor no ensino público, situação absolutamente ajustada a um subsistema de ensino com fins lucrativos e que não são obrigados a limitar a dimensão média das turmas, contrariamente ao que se verifica no ensino público pelo facto de se 
aceitar com Borman e Hewes (2002), Camacho (2006), Krueger (2003), entre outros, que a redução do número de alunos por turma tem efeitos positivos no sucesso educativo.

Em qualquer das circunstâncias registe-se que a evolução dos rácios número de alunos/professor evidencia uma intensificação do trabalho docente que, pelo menos no que respeita ao ensino público e como adiante se verá, não tem sido compensado, nomeadamente em termos salariais.

Vejamos, finalmente, o que se verificou no ensino superior para o que, de seguida, apresenta-se a evolução do número de docentes do ensino superior, público, privado e total e respectivos rácios nํำ de estudantes/professor.

\begin{tabular}{|c|c|c|c|}
\hline Anos & $\begin{array}{l}\text { № docentes ensino } \\
\text { superior público }\end{array}$ & $\begin{array}{l}\text { № docentes ensino } \\
\text { superior privado }\end{array}$ & Total ensino superior \\
\hline 2001 & 24296 & 11444 & 35740 \\
\hline 2005 & 26214 & 11220 & 37434 \\
\hline 2008 & 24728 & 10652 & 35380 \\
\hline 2010 & 26410 & 11654 & 38064 \\
\hline 2011 & 25849 & 11229 & 37078 \\
\hline 2012 & 25528 & 9954 & 35482 \\
\hline 2013 & 24745 & 8753 & 33528 \\
\hline 2014 & 24493 & 7853 & 32346 \\
\hline 2015 & 25142 & 7438 & 32580 \\
\hline
\end{tabular}

Fontes/Entidades: DGEEC/MEd - MCTES, PORDATA

Última actualização: 26/09/2016

Nota: Não se encontraram dados disponíveis para anos anteriores

Como seria de esperar, o número de docentes do ensino superior diminuiu substancialmente ao longo do período, sendo que a situação se agravou a partir de 2010, acompanhando a evolução registada do número de alunos, particularmente no ensino superior privado onde essa quebra foi mais 
significativa, e as políticas de redução das despesas públicas, no ensino superior público.

Esta diminuição do número de docentes, e apesar da quebra ocorrida no número de alunos matriculados no sistema, traduziu-se na intensificação do trabalho docente já que cada professor passou a ter a seu cargo, em média, um maior número de alunos. Observe-se o Tabela 10.

\begin{tabular}{|lccc}
\hline \multicolumn{4}{|c|}{ Tabela 10 - Evolução do rácio número de alunos/professor, no ensino } \\
superior público, no ensino superior privado e total do ensino superior \\
\hline Anos & Ensino superior público & $\begin{array}{c}\text { Ensino superior } \\
\text { privado }\end{array}$ & Total ensino superior \\
\hline 2001 & 11,3 & 10,0 & 10,8 \\
\hline 2005 & 10,8 & 8,8 & 10,2 \\
\hline 2008 & 11,5 & 8,7 & 10,7 \\
\hline 2010 & 11,1 & 7,7 & 10,1 \\
\hline 2011 & 11,9 & 7,9 & 10,7 \\
\hline 2012 & 12,2 & 7,9 & 11,0 \\
\hline 2013 & 12,3 & 7,7 & 11,1 \\
\hline 2014 & 12,3 & 7,7 & 10,7 \\
\hline 2015 & 11,6 & 7,7 & \\
\hline
\end{tabular}

Fontes/Entidades: DGEEC/MEd - MCTES, PORDATA

Nota: Cálculos do autor

A análise da evolução dos rácios $\mathrm{n}^{\mathrm{o}}$ de alunos/professor, total e por subsistema de ensino revela-nos um movimento contraditório conforme o subsistema. Assim, observa-se o crescimento desse rácio, em termos totais e no ensino superior público e um decréscimo, no que respeita o ensino superior privado. No que respeita ao rácio relativo ao total de alunos do ensino superior (público e privado), o acréscimo registado, apesar da diminuição real do número 
de alunos nos últimos anos, decorre da diminuição mais que proporcional do número de docentes, particularmente no ensino superior privado.

No que respeita aos rácios relativos a cada um dos subsistemas, a evolução contrária resulta do facto de o ritmo de decrescimento do número de docentes do ensino superior privado ser muito superior ao registado no ensino superior público, sendo que no subsistema público a diminuição do número de alunos não foi, em termos relativos, tão intensa em virtude de ser muito mais baixa a taxa de frequência nestas instituições do que nos estabelecimentos privados de ensino superior. Estas diferenças resultam, como referido anteriormente, do facto de a crise económica e financeira que o país vive desde 2008 terem levado muitos candidatos ao ensino superior a não se candidatarem por incapacidade financeira, facto que afecta com maior agressividade o ensino superior privado em virtude dos elevados custos associados à sua frequência.

Dos dados se percebe que, e no que respeita ao ensino superior público, se tem vindo a assistir a um processo de intensificação do trabalho docente que, como se verá na secção seguinte e à semelhança do que se ocorre com os professores do ensino básico e secundário público, não tem tido qualquer compensação, nomeadamente ao nível salarial.

\section{A proletarização docente: o caso do ensino público em Portugal}

Pela exposição anterior é possível perceber que a educação em Portugal tem vindo a sofrer profundas mudanças desde finais do século XX. Essas mudanças testemunham avanços e recuos seja na procura social de educação seja no número de docentes associados, quer no ensino público quer no ensino privado.

Estas alterações, particularmente desde inícios do novo século, têm vindo a ser acompanhadas de um processo contínuo de desvalorização da carreira docente, independentemente do nível de ensino.

De seguida, apresenta-se, a propósito, a evolução dos salários dos professores dos ensinos básico e secundário, e superior, na oferta pública uma vez que relativamente ao ensino privado a informação não se encontra disponível.

No que respeita ao vencimento dos docentes do ensino público, impõe-se que se apresentem duas notas a fim de tornar mais inteligível a análise. 
Em primeiro lugar, é de destacar que existem duas carreiras docentes, a dos professores do ensino não superior (pré-escolar e ensino básico e secundário) e do ensino superior (com ligeiras alterações consoante se trata do ensino superior universitário ou do ensino superior politécnico). Em segundo lugar, regista-se que cada uma das carreiras é única, o que significa que os salários e demais condições contratuais dos professores da educação pré-escolar e dos ensinos básico e secundário praticados são iguais em qualquer escola pública do país, em igualdade de condições no âmbito da carreira; de igual modo, o salário e demais condições laborais é igual para todos os docentes do ensino superior público, independentemente da instituição pública em que exercem.

Independentemente da carreira que se analise, cada uma delas é constituída por diversos escalões que se diferenciam pelo tempo de serviço, qualificações, formação, etc. de cada indivíduo. Apenas a título de exemplo, no que respeita aos professores do ensino não superior, a entrada na carreira exige que possuam um mestrado na área específica de ensino para a qual concorrem e o concurso, de natureza nacional, coloca os candidatos numa lista ordenada em função da avaliação da formação académica (da graduação e da pós-graduação), da formação profissional frequentada e de experiência profissional já detida e a carreira faz-se ao longo de 10 escalões.

No caso da carreira docente universitária ela é constituída por: Professor Auxiliar, Professor Associado, Professor Catedrático, sendo que em cada categoria existe uma prova académica, a de agregação e que é condição indispensável para ascender ao cargo de professor catedrático e que cada uma dessas categorias é também constituída por um número variável de escalões. Para iniciar a carreira, no cargo de Professor Auxiliar, o candidato tem de possuir o doutoramento na área de abertura da vaga e os concursos para qualquer dos cargos são públicos e abertos a candidatos nacionais ou estrangeiros e aprovados por mérito absoluto em provas públicas.

Tendo em conta as diversas posições de carreira possíveis para os docentes, para melhor se perceber a forma como o seu trabalho se tem vindo a desvalorizar, tomamos em consideração, apenas, três situações: $3^{\circ}$ e $10^{\circ}$ escalões, que representam a situação de início e o final de carreira do ensino básico e secundário e o de professor associado sem agregação do ensino superior universitário. 
Tabela 11 - Evolução dos salários nominais dos professores do $3^{\circ}$ e $10^{\circ}$ escalão do ensino básico e secundário (EBS) e de professor associado sem agregação, 1 escalão, do ensino superior universitário (ESU), em euros

\begin{tabular}{|c|c|c|c|}
\hline Período & Prof. EBS - 3 Escalão & Prof. EBS - 100 Escalão & $\begin{array}{c}\text { Prof. ESU - Associado } 10 \\
\text { escalão }\end{array}$ \\
\hline 2010 & $1.864,19$ & $3.364,60$ & 4010,23 \\
\hline 2011 & $1.864,19$ & $3.364,60$ & 4010,23 \\
\hline 2012 & $1.864,19$ & $3.364,60$ & 4010,23 \\
\hline 2013 & $1.864,19$ & $3.364,60$ & 4010,23 \\
\hline 2014 & $1.864,19$ & $3.364,60$ & 4010,23 \\
\hline 2015 & $1.864,19$ & $3.364,60$ & 4010,23 \\
\hline 2016 & $1.864,19$ & $3.364,60$ & 4010,23 \\
\hline 2017 & $1.864,19$ & $3.364,60$ & 4010,23 \\
\hline
\end{tabular}

Fonte: Sindicato dos Professores da Grande Lisboa/FENPROF; PORDATA

A simples leitura dos dados do Tabela 11 explicitam, bem a proletarização contínua da carreira docente. Utilizando os dados disponíveis, apresenta-se no quadro a forma como evoluíram os salários dos docentes dos ensinos superior e não superior desde a crise sendo que esta evolução se carateriza, exactamente, pela sua estagnação.

Desde há alguns anos que os salários dos professores do ensino público em Portugal, independentemente do nível de ensino e do escalão profissional, que não conhecem qualquer alteração. Pelo contrário, considerando as políticas de austeridade seguidas entre 2011 e 2015 pelos governos ultraliberais de então, os salários, para além de "congelados" ainda foram cortados, isto é, o governo aplicou um imposto adicional ao salário docente que retirou a estes profissionais cerca de $10 \%$ do vencimento mensal (bem como aos restantes funcionários públicos e aos aposentados da função pública).

A estes cortes acresce, ainda, o congelamento dos subsídios de férias e de Natal que aqueles governos estabeleceram. Apenas a partir de 2016 a situação se tem vindo a normalizar, tendo o novo governo nascido das eleições legislativas de 
Outubro de 2015, de natureza socialista apoiado pelo Partido Comunista e pelo Bloco de Esquerda, vindo a inverter, gradualmente, a situação.

\section{Conclusão}

A análise anterior pretendeu apresentar um panorama do estado do ensino, em Portugal, desde finais do século XX. Ao longo do artigo percebeu-se que a partir da Revolução Democrática de 1974, o país mudou e que, com essa mudança muito se alterou na educação. A procura de educação cresceu de forma explosiva durante algumas décadas, seja da educação básica e secundária, seja da de nível superior. As taxas bruta e real de escolarização dos portugueses aumentaram de forma significativa. 0 número de docentes aumentou, acompanhando aquela procura.

O exposto mostra, também, um processo lento, mas gradual, de privatização da educação, mormente da educação superior. A uma oferta pública de ensino superior, até 1986, assiste-se à abertura do ensino superior à iniciativa privada nessa data e, a partir de 1992, ao estabelecimento de taxas de frequência actualizadas no ensino superior público.

Por outro lado, verificou-se a partir de inícios do século XXI, uma diminuição da procura educativa, decorrente fundamentalmente, da questão demográfica concretizada na diminuição do número de nascimentos, no caso da educação básica e secundária; e da crise económica e financeira que o país tem vindo a atravessar acompanhado de fortes medidas ultraliberais de austeridade, em especial de ensino superior.

Finalmente, a exposição mostrou a diminuição do número de docentes nos diversos níveis e subsistemas de ensino que, e apesar da diminuição do número de alunos matriculados, implicou uma elevação do rácio número de estudantes/professor em todo o ensino público. Contrariando este indicador de intensificação do trabalho docente, ocorre um movimento inverso no que respeita ao ensino superior privado, decorrente da diminuição muito significativa do número de alunos matriculados neste subsistema de ensino.

Para terminar, o artigo explicita a evolução do vencimento dos professores do ensino público, de nível superior e não superior, que evidencia um forte processo de desvalorização da carreira na última década, fruto de medidas ultraliberais de contracção das despesas públicas. De alguma forma, Portugal tem vindo a obedecer bem ao que Dale (2004) refere como "agenda global para a educação". 
Em jeito de conclusão, pode afirmar-se que os caminhos da educação no país têm sido percorridos por influências de sentido contrário que se traduziram na intensificação e proletarização do trabalho docente, sendo expectável que a situação se inverta, ainda que de forma lenta, decorrente da natureza mais social do governo em vigor, governo formado pelo Partido Socialista e apoiado no parlamento pelo Partido Comunista Português e o Bloco de Esquerda, que resultou das eleições legislativas de Outubro de 2015 e que veio resgatar a esperança dos Portugueses.

\section{Referências}

BARROSO, J. Organização e regulação dos ensinos básico e secundário, em Portugal: sentidos de uma evolução. Educação \& Sociedade, vol. 24, no 82, 6392, 2002.

BAUDELOT, C. \& ESTABELET, R. L'École capitaliste en France. Paris : Maspero, 1971

BECKER, G. Human Capital - A Theoretical and Empirical Analysis, with Special Reference to Education. New York: Columbia University Press, 1964.

BORMAN, G.; HEWES, G. The long-term effects and cost-effectiveness of Success for All. Educational Evaluation and Policy Analysis, 24(4), 243-266, 2002.

BOUDON, R. L'inégalité des chances. Paris : Pluriel, 1973.

BOURDIEU, P. ; PASSERON, J. C. Les héritieres: les étudiants et la culture. Paris: Éditions de Minuit, 1964.

CABRITO, B. G. A Educação em Portugal - Caminhos Recentes e Tendências Futuras. In: SCAFF, Elisângela; FONSECA, Marília (Orgs.). Gestão e Planejamento da educação básica nos cenários nacional e internacional. São Paulo: Mercado de Letras, 2016, pp. 205-234.

CABRITO, B. 0 Financiamento do Ensino Superior. Lisboa: EDUCA, 2002.

CAMACHO, C. M. Class size reduction: is it worth the cost? A meta-analysis of the research. Orlando, Florida: College of Education at the University of Central Florida, 2006. 
CERDEIRA L.; CABRITO B.; MACHADO-TAYLOR M. L.; GOMES R. A Fuga de Cérebros em Portugal: Hipóteses Explicativas. Revista Brasileira de Política e Administração da Educação. Vol. 31, n. 02 de 2015, pp. 408-419, 2015.

CERDEIRA, L.; CABRITO, B.; MACHADO-TAYLOR, M. L.; PATROCÍNIO, T. Transferência de investimento na educação com base no custo livre: alguns dados de Portugal, Espanha, Grécia e Itália. Ensaio: aval. pol. públ. Educ., Rio de Janeiro, v.24, n. 93, p. 777-803, out./dez. 2016.

DALE, R. Globalização e educação: demonstrando a existência de uma "cultura educacional mundial comum" ou localizando uma "agenda globalmente estruturada para a educação?" Educação \& Sociedade, Campinas, SP, v. 25, n. 87, p. 423-460, maio/ago. 2004.

DOERINGER, P.; PIORE, M. Internal Labor Markets and Manpower Analysis. Lexington: Heath and Co., 1971.

GOMES, R. M. et alli. "L'emigration portugaise qualifiée dans le contexte européen", Hommes \& Migrations, 1317-18 (double). avril-septembre/2017.

KRUEGER, A. B. Economic considerations and class size. Economic Journal, 113, $34-63,2003$.

MÓNICA, M. F. Educação e Sociedade no Portugal de Salazar (1926-1939). Lisboa: Presença-Gis, 1978.

SCHULTZ, T. Investment in Human Capital. American Economic Review, no 51 , pp. 1-16, 1961.

Enviado em 28/07/2017

Aprovado em 09/08/2017 